\title{
Análise do impacto da alteração normativa na aposentadoria por invalidez no Brasil
}

An analysis of the impact of the normative change in disability retirement in Brazil

\begin{abstract}
We investigate the response of federal civil servants to more stringent rules for disability retirement introduced by the Constitutional Amendment 41/2003 (EC 41/2003). First, we look for changes in the health conditions of Brazilians so to speculate on their effects on the use of disability benefit in Brazil. Then, we use those results in setting the control variables of econometric models we use to compare the behavior of civil servants (treatment group) and private sector workers (control group) in terms of the number and incidence of retirement disability. Based on difference in differences (DID) estimates, we conclude that civil servants responded to the incentive created with the new rules by preventing disability retirements and, thus, mitigating the moral hazard problem of social security.
\end{abstract}

\section{Keywords}

social security, disability retirement, difference-in-differences, incentives, moral hazard.

JEL Codes A13; D71; H55.
Helvio Antonio Pereira Marinho

Superintendência Nacional de Previdência Complementar

Moises de Andrade Resende Filho

Universidade de Brasília

Vander Mendes Lucas

Universidade de Brasília

\section{Resumo}

Investiga-se a resposta dos servidores públicos federais a regras mais restritivas nas aposentadorias por invalidez, introduzidas pela Emenda Constitucional $n^{0}$ 41/2003 (EC 41/2003). Inicialmente, investigam-se potenciais alterações nas condições de saúde dos brasileiros de modo a especular sobre seus efeitos na utilização de beneficios por invalidez no Brasil. Em seguida, os resultados dessa investigação inicial são utilizados na definição das variáveis de controle dos modelos econométrico utilizados para comparar o comportamento dos servidores públicos (grupo tratado) com o dos trabalhadores do setor privado (grupo controle) em termos do número e incidência de aposentadorias por invalidez. Com base nas estimativas de diferença em diferenças (DD), conclui-se que os servidores públicos responderam aos incentivos criados com as novas regras, evitando a aposentadoria por invalideze, assim, mitigando o problema de risco moral da Previdência Social.

\section{Palavras-chave}

Previdência Social; aposentadoria por invalidez; diferença em diferenças; incentivos; risco moral.

Códigos JEL A13; D71; H55. 


\section{Introdução}

A Previdência Social é uma importante política social ao garantir a manutenção da condição econômica do trabalhador ao se aposentar e, assim, o seu bem-estar. No entanto, a Previdência Social tem sido objeto de permanente preocupação dos governos no Brasil por conta dos seus constantes déficits e dos perigos que trazem ao equilíbrio das contas nacionais. Tal realidade tem ensejado mudanças nas normas, inclusive constitucionais, de modo a reduzir os custos previdenciários com a redução dos benefícios dos futuros aposentados, inclusive daqueles do setor público (Najberg; Ikeda, 1999). Por exemplo, a Emenda à Constituição n 41 de 2003 (EC 41/2003), que entrou em vigor a partir de janeiro de 2004, alterou as regras de concessão de aposentadorias por invalidez no serviço público, reduzindo o valor do benefício das aposentadorias futuras.

Tendo em vista que a concessão do benefício da aposentadoria por invalidez é de risco, ou seja, decorre de um problema inesperado grave de saúde ou devido a um acidente, seria razoável antecipar um efeito nulo da EC 41/2003 no número e incidência de aposentadorias por invalidez no serviço público.

O presente trabalho tem por objetivo principal testar a hipótese de que a EC 41/2003 não teve efeito no número e incidência de aposentadorias por invalidez dos servidores públicos. Para tanto, utilizamos o estimador diferença em diferenças para comparar o comportamento das séries do número e incidência de aposentadorias por invalidez dos servidores públicos (grupo tratado) com as dos trabalhadores da iniciativa privada (grupo controle, pois não foram afetados pela EC 41/2003). Com base nas estimativas obtidas, constatamos que os servidores públicos reagiram às alterações das regras evitando a aposentadoria por invalidez, mesmo quando esta se mostrava inevitável.

Este trabalho está organizado da seguinte maneira: a segunda seção apresenta os regimes da Previdência Social no Brasil e as alterações ocorridas em suas normas de concessão; a terceira seção investiga se há alterações em curso nas condições de saúde e os potenciais efeitos delas na utilização de benefícios por invalidez e conjectura, com base na literatura, sobre a reação esperada dos agentes econômicos a mudanças de regras que alteram os incentivos; com base em análises gráficas e econométricas, a quarta seção apresenta e discute as estimativas diferença 
em diferenças para os efeitos da EC 41/2003 no número e incidência de aposentadorias por invalidez no serviço público, tomando os trabalhadores do setor privado como grupo controle; e, por fim, a última seção apresenta as principais conclusões do trabalho, destacando o efeito de regras mais restritivas sobre o número e incidência de aposentadorias por invalidez no serviço público.

\section{Estrutura e alterações normativas da Previdência Social no Brasil}

No Brasil, a Previdência Social apresenta três regimes, quais sejam: o Regime Geral de Previdência Social (RGPS), com caráter contributivo e de filiação obrigatória para os empregadores, empregados assalariados, domésticos, autônomos, contribuintes individuais e trabalhadores rurais; o Regime Próprio de Previdência Social (RPPS), compulsório para o servidor público do ente federativo que o tenha instituído e que não inclui os empregados das empresas públicas, os agentes políticos, servidores temporários e detentores de cargos de confiança, os quais são todos filiados obrigatoriamente ao RGPS; e o Regime de Previdência Complementar (RPC), que se diferencia dos demais, principalmente por ser facultativo. O RPC é, em parte, operado por entidades abertas em que a entrada é livre a qualquer indivíduo e por Entidades Fechadas de Previdência Complementar (EFPC) ou fundos de pensão em que a entrada é limitada aos empregados das empresas patrocinadoras e associados ou membros de associações, entidades de caráter profissional, classista ou setorial, chamadas de instituidoras. A principal característica da parte do RPC operada pelas EFPC é a coparticipação, ou seja, como no RPPS e RGPS, a empregadora participa junto com seu funcionário no fundo previdenciário da EFPC, naquilo que exceder o teto do INSS.

\subsection{Alterações nas regras da Previdência Social à época da EC $41 / 2003$}

Os gastos com benefícios previdenciários no Brasil atingiram 11\% do PIB em 2006, patamar próximo ao de países com uma população bem maior 
de idosos, como Reino Unido e Holanda (Zylberstajn et al., 2010). A deterioração do sistema previdenciário brasileiro também pode ser constatada pelo fato de a razão contribuintes/beneficiários ter passado de 31 contribuintes para cada beneficiário, por volta dos anos de 1940, para menos de dois contribuintes na ativa para cada beneficiário em 2004 (Oliveira et al., 2004). Ainda, estima-se que a parcela da população com 67 anos ou mais deverá quadruplicar até 2047, o que aumentará a magnitude dos gastos com aposentadoria, tornando a reformulação do sistema uma condição necessária para correção do equilíbrio fiscal (Zylberstajn et al., 2010).

Nesse contexto, o RPPS tem sido foco de muita discussão por ser considerado o regime mais caro e um dos causadores da má distribuição de renda no Brasil (Caetano, 2015). Por conta disso, as grandes mudanças ocorridas no RPPS nas últimas décadas foram no sentido de torná-lo mais restritivo. Entre as alterações, destaca-se a EC 41/2003, que alterou as regras de aposentadoria dispostas no art. 40 da Constituição Federal de 1988, inclusive as relacionadas à aposentadoria por invalidez.

As mudanças propostas na EC 41/2003 foram disciplinadas por meio da Medida Provisória n ${ }^{\circ} 167$, de 19 de fevereiro de 2004, convertida na Lei ${ }^{\circ}$ 10.887 de 18 de junho de 2004 (Marco et al., 2009). Com isso, a partir de 2004, a base de cálculo dos proventos passou a ser a mesma vigente para o RGPS, qual seja: a média aritmética das remunerações utilizadas como base para as contribuições do servidor a todos os regimes de previdência a que esteve vinculado. Para tanto, são utilizadas as maiores remunerações de contribuição, correspondentes a $80 \%$ (oitenta por cento) de todo o período, desde a competência de julho de 1994 (Marco et al., 2009). Além disso, deixou de haver garantias de o aposentado receber os mesmos reajustes dos servidores ativos, o fim da paridade no RPPS, mesmo para os ingressos antes de 2004, que teriam paridade só na aposentadoria programada e não por invalidez.

Antes da EC 41/2003, a base de cálculo da aposentadoria por invalidez era a última remuneração do servidor no cargo efetivo em que ocorreu a aposentadoria. Os proventos eram integrais nos casos de acidentes de trabalho, doenças profissionais e doenças definidas em lei como graves; ou eram proporcionais ao tempo de contribuição, mas sempre calculados sobre a última remuneração, caso a invalidez tivesse sido causada por outras doenças. Vale lembrar que a EC 47/2005 criou uma nova regra de transição para servidores que tenham ingressado no serviço público até 31/12/2003. 
Essa alteração resguarda a paridade e o cálculo dos proventos integrais, mas somente para os servidores com idades e tempos de contribuição já completos, além de outros requisitos. Aqueles que não completassem todos os requisitos em razão de invalidez ficariam sem essas garantias.

Com a EC 41/2003, a União passou a conceder aposentadorias por invalidez significativamente menores no caso de doenças graves, profissionais e acidentárias e aposentadorias ainda menores quando a invalidez era gerada por doenças não graves definidas segundo a lei. Mas no caso do RGPS, entre 2001 e 2012, não houve qualquer alteração na legislação com impacto no valor do benefício devido ao segurado em caso de incapacidade para o trabalho. Por isso, a renda mensal recebida como aposentadoria por invalidez continuou sendo calculada à base de $100 \%$ sobre o salário de benefício, ${ }^{1}$ podendo ser acrescido de $25 \%$, caso o beneficiário necessite de auxílio permanente de uma pessoa.

\section{Resposta dos agentes a incentivos}

Nesta seção, investigam-se alterações nas condições de saúde da população brasileira e nas regras de concessão do benefício, de modo a nos permitir especular sobre seus potenciais efeitos na utilização de benefícios por invalidez. Com isso, busca-se detectar fatores que possam justificar variações no número e incidência de aposentadorias por invalidez no país e que devem ser incorporados aos modelos econométricos utilizados no presente artigo.

\subsection{0 papel das condições de saúde na utilização de benefícios por doença}

Com relação ao efeito das condições de saúde na utilização de benefícios por doença, espera-se uma redução (aumento) na utilização do benefício da aposentadoria por invalidez em caso de melhora (piora) das condições gerais de saúde da população. Por isso, é importante investigar a evolução das condições de saúde da população, analisando, como sugerem Jönsson 1 Média apurada sobre os salários de contribuição, corrigidos mensalmente, dos maiores salários de contribuição de $80 \%$ do período contributivo. 
et al. (2010), o comportamento da taxa de mortalidade e da utilização de cuidados médicos segundo o número de internações no tempo. Com vistas a efetuar essa análise para o Brasil, primeiramente, o Gráfico 1 apresenta as séries da participação anual por faixa etária na mortalidade de 1998 a 2012.

\section{Gráfico 1 Evolução da participação anual por faixa etária na taxa de mortalidade no}

\section{Brasil, 1998 a 2012}

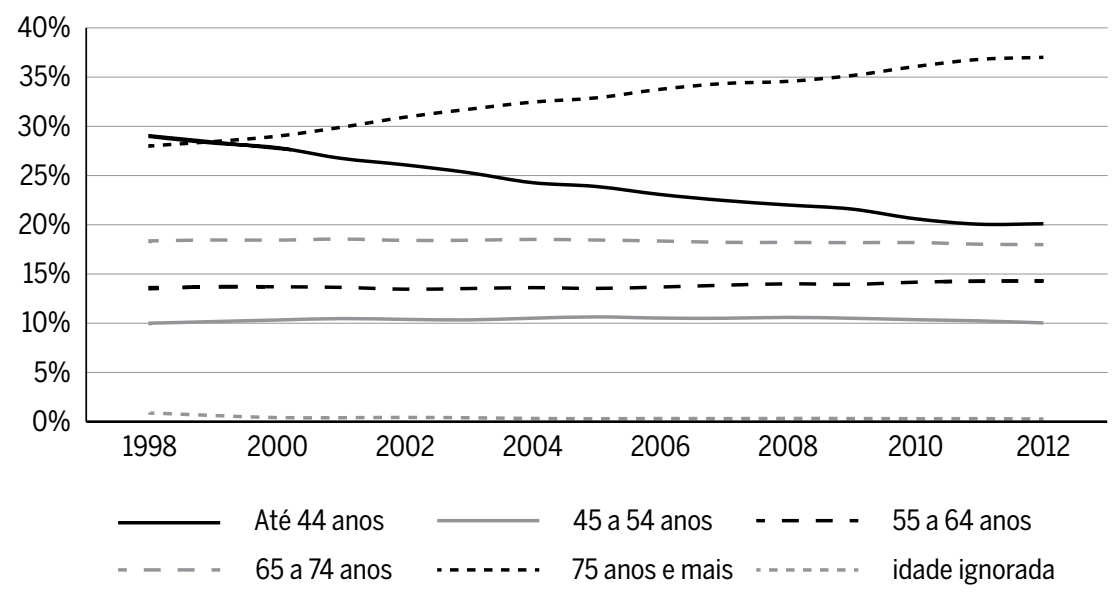

Fonte: Departamento de Informática do SUS (DATASUS).

Pelo Gráfico 1, percebe-se que de 1998 a 2012 há uma redução de quase $10 \%$ da participação anual da faixa etária até 44 anos na taxa de mortalidade, ao mesmo tempo em que há um aumento de quase $10 \%$ na participação da faixa etária de 75 anos e mais, com as demais faixas etárias se mantendo em patamares praticamente constantes ao longo do período. Diante disso, fica evidente que os brasileiros passaram a falecer com idades mais avançadas ao longo do período.

Em seguida, o Gráfico 2 apresenta o número de 100 mil internações por mês registradas no Sistema Único de Saúde (SUS) e a média mensal de dias de permanência em internações hospitalares² de 1998 a 2012, como proxies para o "uso de cuidados médicos no Brasil", mostrando que permanecem praticamente inalterados no período. 
Gráfico 2 Evolução da média mensal de dias de permanência em internações hospitalares e do número mensal de 100 mil internações no Brasil, janeiro de 1998 a dezembro de 2012

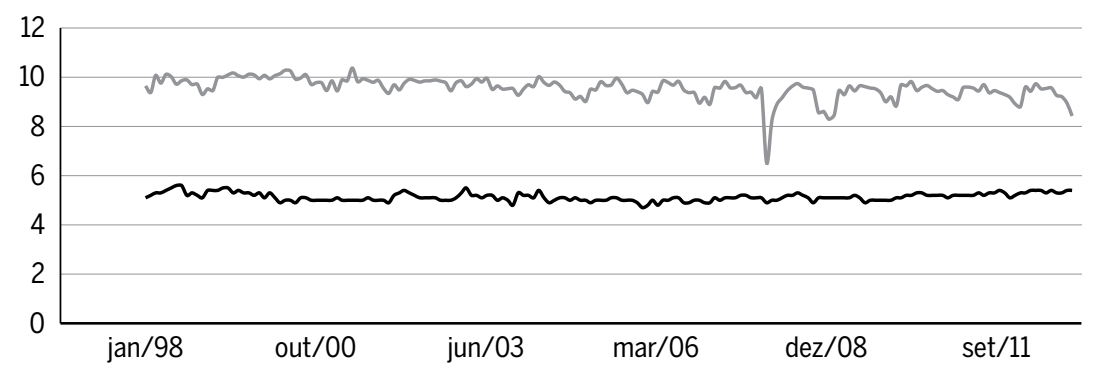

- Média de Permanência de interações hospitalares (em dias)

— Número de 100 mil internações

Fonte: Departamento de Informática do SUS (DATASUS).

Portanto, a manutenção ou redução na taxa de mortalidade das faixas etárias dos indivíduos em idade de trabalho (Gráfico 1), a manutenção da média mensal de dias de permanência em internações hospitalares e uma tendência de queda no número de internações (Gráfico 2) em um contexto de aumento populacional sugerem uma tendência de redução no número e incidência de aposentadorias por invalidez.

\subsection{As alterações de regras e a utilização de benefícios}

Entre os fatores que influenciam a decisão dos agentes sobre a requisição de benefícios, destacam-se o grau de proteção, isto é, o quanto o segurado recebe no caso fortuito e a elegibilidade, ou seja, os critérios que devem ser atendidos para que o segurado se torne elegível ao recebimento do benefício (Jönsson et al., 2010). Por exemplo, Jönsson et al. (2010) identificaram a antecipação no uso do benefício pelos agentes segurados diante da comunicação de aumento no rigor das regras de concessão (elegibilidade) na Suécia na década de 90. Já no Brasil, a redução nos benefícios (grau de proteção) dos servidores que optassem pela aposentadoria proporcional, resultou, após a reforma previdenciária de 1998, em uma queda de 58\% nas aposentadorias proporcionais (Pessoa; Tafner, 2006). 
Para dar início à investigação sobre se efeitos similares a esses ocorreram em decorrência das modificações propostas pela EC 41/2003, com vigência a partir de janeiro de 2004, utiliza-se o Gráfico 3.

\section{Gráfico 3 Evolução do número anual de aposentadorias integrais e proporcionais no RPPS antes e depois da EC 41/2003, 2001 a 2012}

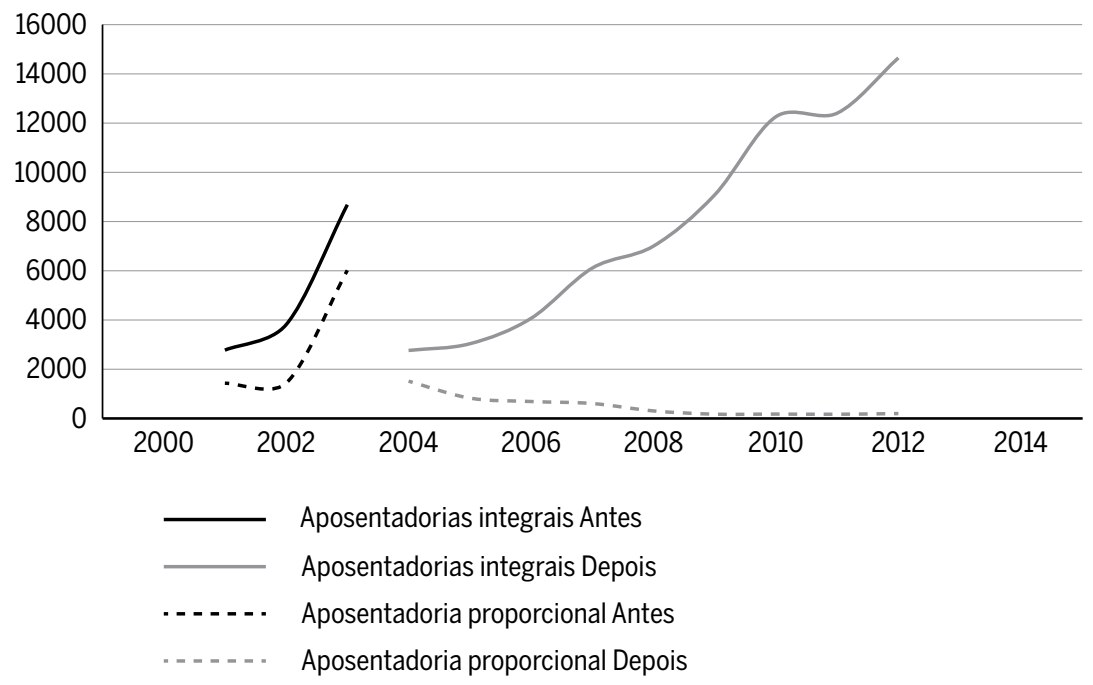

Fonte: Elaboração própria com dados do BEP/MPOG.

Pelo Gráfico 3, fica evidente a quebra estrutural nas séries anuais do número de aposentadorias integrais e proporcionais (aposentadorias programadas) no RPPS no ano de 2004. Para confirmar isso, aplicamos o teste de quebra estrutural endógena de Zivot e Andrews (1992) para raiz unitária ${ }^{3}$ nas séries do número mensal de aposentadorias integrais e proporcionais e encontramos uma quebra estrutural no mês de janeiro de 2004 em cada série, pois, nesses pontos as estatísticas $t$ dos testes Dickey-Fuller aumentado (ADF) apresentaram os valores mínimos -7,332 e -6,993 (ambos significantes a 1\%).

A nossa hipótese é que a quebra estrutural nas séries do número de aposentadorias integrais e proporcionais no RPPS com um pico no número 3 O teste de Zivot e Andrews (1992) consiste em, sequencialmente, realizar testes Dickey-Fuller aumentado (ADF), empregando uma variável dummy para cada possível data de quebra estrutural. A data de quebra é selecionada quando a estatística $t$ do teste $\mathrm{ADF}$ alcança um mínimo (o valor mais negativo). Ou seja, a data de quebra é selecionada onde há a menor evidência favorável à hipótese de raiz unitária. 
de tais aposentadorias em 2003 (vide Gráfico 3) se deve à antecipação dos agentes às alterações proposta pela EC 41/2003, as quais passam a vigorar a partir de 01 de janeiro de 2004. Contudo, a partir de 2004, já se evidencia uma tendência de aumento no número de aposentadorias integrais e uma tendência de redução no número de aposentadorias proporcionais ${ }^{4}$ (vide Gráfico 3), o que nos leva a supor que ocorram devido à migração das aposentadorias proporcionais e por invalidez para a aposentadoria integral. ${ }^{5}$

Pelo Gráfico 4, observamos que há um grande aumento no número anual de aposentadorias por invalidez também no RPPS nos anos que imediatamente antecedem 2004, seguindo-se uma tendência de queda nos períodos subsequentes.

\section{Gráfico 4 Número anual de aposentadorias por invalidez no RPPS, 2001 a 2012}

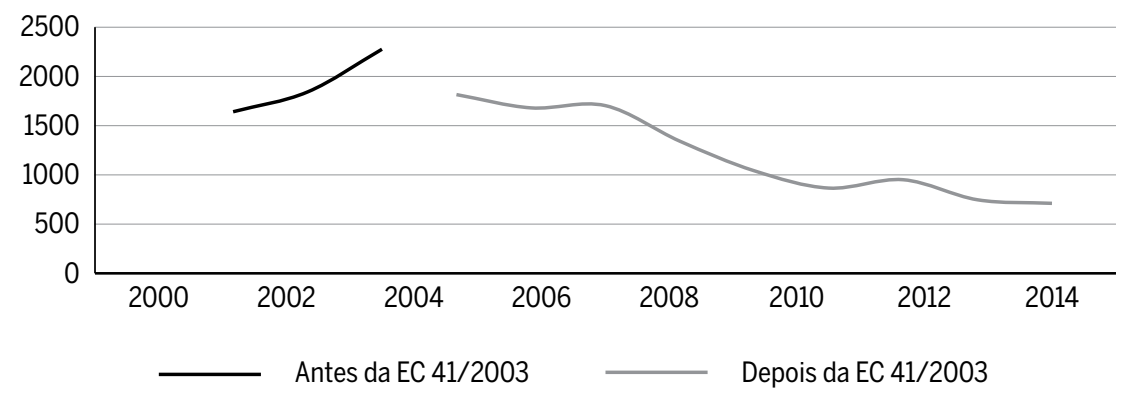

Fonte: Elaboração própria com dados do BEP/MPOG.

De fato, aplicando o teste de quebra estrutural endógena de Zivot e Andrews (1992) para raiz unitária nas séries logaritmo natural e número mensal de aposentadorias por invalidez no RPPS, encontramos uma quebra estrutural em cada uma dessas séries no mês de maio de 2003, quando as estatísticas $t$ dos testes Dickey-Fuller aumentado (ADF) apresentam os valores mínimo -6,725 e -6.995 (ambos significantes a 1\%).

Os padrões observados nos Gráficos 3 e 4 dão indícios a favor da hipótese de que a piora nas regras de concessão com a EC 41/2003 foi responsável pela tendência de queda no número de aposentadorias por invalidez

$4 \mathrm{Tal}$ fato é reforçado pelo art. $2^{\circ}$ da EC 41/2003, que torna as regras de transição mais rígidas para aposentadorias com proventos proporcionais.

5 Pessoa e Tafner (2006) discutem um fenômeno similar, mas com relação à migração das aposentadorias proporcionais para as por invalidez, após a reforma previdenciária de 1998. 
no RPPS, observada a partir de 2004. Contudo, cientes de que fatores comuns aos trabalhadores no RPPS e RGPS podem também ter influenciado tal comportamento, buscamos reduzir o máximo possível o potencial confundidor, utilizando o estimador diferença em diferenças nas análises da seção 4 do presente trabalho. Para tanto, utilizam-se os trabalhadores no RGPS como grupo controle, uma vez que a EC 41/2003 não afetou em nada as regras de aposentadoria desse grupo.

\section{0 comportamento da aposentadoria por invalidez no Brasil após a EC 41/2003}

Uma forma de classificar o benefício previdenciário é distingui-lo entre benefício programável e benefício de risco. Fazem parte do primeiro grupo as aposentadorias integral e proporcional, e do segundo, a aposentadoria por invalidez, pensão e auxílios de modo geral (auxílio-doença, auxílio reclusão etc.).

O benefício programável tem sua utilização condicionada às exigibilidades legais e à decisão de se aposentar do participante, até o limite de 70 anos, ${ }^{6}$ quando o servidor é aposentado compulsoriamente. Já o benefício de risco não deveria depender da vontade do beneficiado, pois o evento gerador do benefício se dá de forma aleatória, como um acidente ou o desenvolvimento de doenças incapacitantes. Portanto, alterações nas regras de utilização desse benefício não deveriam causar mudanças significativas nas aposentadorias por invalidez, mesmo quando reduzem os valores a serem auferidos nos casos de incapacitação para o trabalho. ${ }^{7}$ Contudo, para testar tal hipótese, deve-se avaliar como os agentes responderam à alteração feita na regra da aposentadoria em 2004, aproximando, caso haja alguma mudança, o quantitativo de servidores públicos que evitaram a aposentadoria por invalidez devido à nova regra.

6 A EC 88/2015 prevê o aumento da idade para a aposentadoria compulsória do servidor público em geral de 70 para 75 anos, porém, carece de regulamentação e não afeta o período analisado neste trabalho.

7 As dez primeiras causas de aposentadorias por invalidez no RGPS são devido a enfermidades graves (Meziat Filho e Silva, 2011), o que deve dificultar para alguém com uma dessas enfermidades a ocultação da sua condição. Ainda, o trabalhador que solicita com frequência afastamentos por motivos de saúde corre o risco de ser aposentado compulsoriamente por invalidez. Em suma, apesar de não termos como quantificar, supomos ser pequeno o número de trabalhadores que, mesmo elegíveis para a aposentadoria por invalidez, conseguem não se aposentar. 


\subsection{Análise gráfica}

Como visto no Gráfico 4, após a vigência da EC 41/2003, o número anual de aposentadorias por invalidez decresce no RPPS, o que não se reflete na participação percentual anual dos tipos de aposentadoria devido à antecipação das aposentadorias programadas, como evidenciado pelo Gráfico 5. Provavelmente, os servidores já elegíveis à aposentadoria programada (integral e proporcional) em 2003 optaram por se aposentar imediatamente e, assim, não diluíram suas saídas ao longo dos anos subsequentes, como usual, acabando por concentrá-las em 2003. De fato, o número de aposentadorias voluntárias (integrais e proporcionais) passou de 6.920 em 2002 para 14.833 em 2003, um aumento de 114\% em relação ao ano anterior. Como consequência, diminuiu o número de aposentadorias voluntárias em relação aos demais tipos de aposentadoria nos anos subsequentes. Consequentemente, por exemplo, aumentou a participação percentual da aposentadoria por invalidez do RPPS de 2003 para 2004, apesar de o número de aposentadorias por invalidez ter diminuído. Assim, devido à possibilidade de fenômenos como esse, optamos por concentrar as nossas análises econométricas no número e incidência de aposentadorias por invalidez.

\section{Gráfico 5 Evolução da participação percentual anual dos tipos de aposentadorias no}

\section{RPPS, 2001 a 2012}

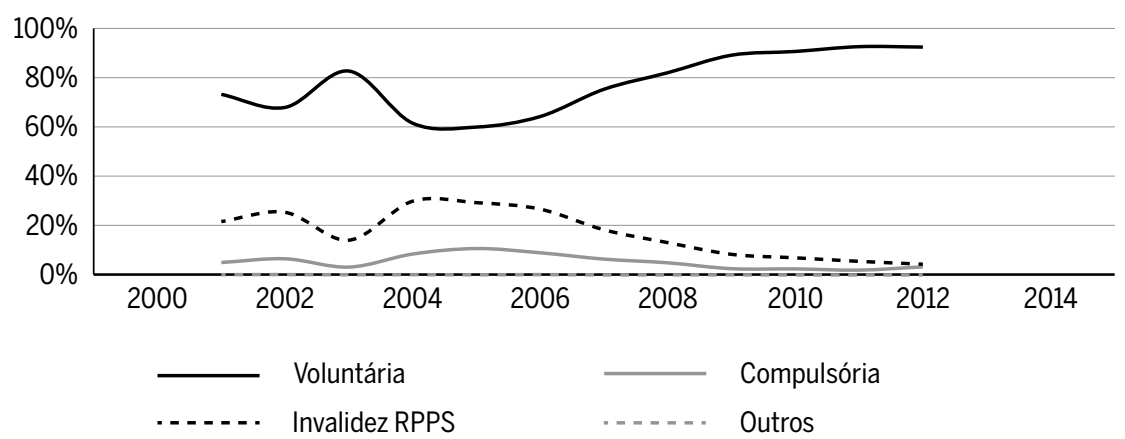

Fonte: Elaboração própria com dados do BEP/MPOG.

Pelo Gráfico 6, é possível observar que a participação percentual anual das aposentadorias por invalidez no RGPS apresenta uma menor oscilação que 
no RPPS e, ao contrário do que ocorre no RPPS, não apresenta uma ruptura em 2004.

\section{Gráfico 6 Evolução da participação percentual anual dos tipos de aposentadorias no}

\section{RGPS $^{8}, 2001$ a 2012}

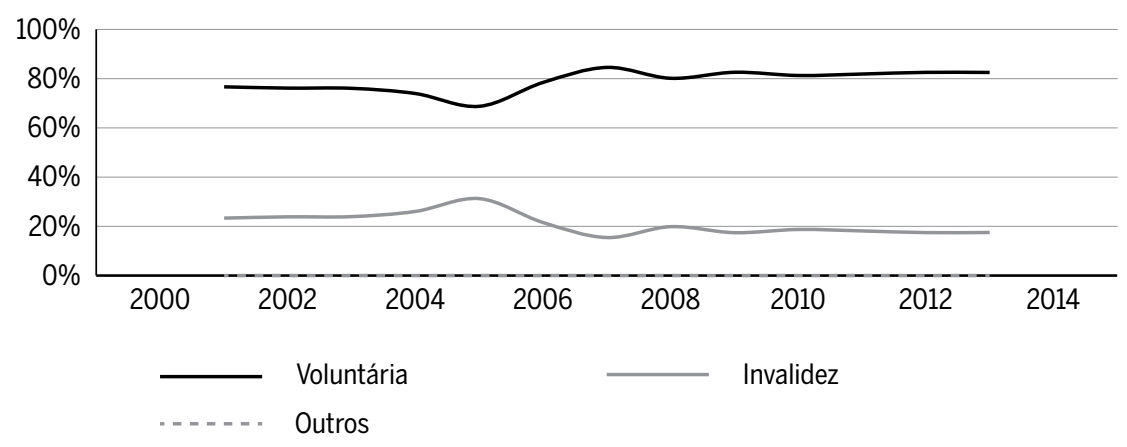

Fonte: Elaboração própria com dados do Anuário Estatístico da Previdência Social (AEPS) InfoLogo.

Apesar de também haver uma tendência de crescimento no primeiro período, entre 2001 e 2003, e uma tendência linear de baixa entre 2004 e 2012, o resultado ao longo do período de 2001 a 2012 é uma queda de $5,9 \%$ na participação percentual das aposentadorias por invalidez no RGPS (vide Gráfico 6). De fato, a queda na participação percentual das aposentadorias por invalidez no RGPS entre 2005 e 2007 se deve, provavelmente, ao fato de os médicos que recebiam por perícia terem sido substituídos por médicos peritos do quadro do INSS nesse período (Meziat Filho; Silva, 2011).

Pelo Gráfico 7, em que o eixo vertical esquerdo é para casos no RPPS e o eixo vertical direito para casos no RGPS, evidencia-se a divergência nas tendências de aposentadorias por invalidez nos dois regimes. A série no RPPS apresenta uma tendência de queda, especialmente após 2004, o que sugere que essa queda pode ter como origem as novas regras de aposentadoria dos servidores públicos (EC 41/2003). Enquanto isso, a série no RGPS apresenta uma tendência de crescimento de 2001 a 2008, quando, a partir de 2009, se estabiliza. Optamos por utilizar o número de aposentadorias por invalidez dos trabalhadores urbanos do RGPS, pois o perfil dos 8 A Aposentadoria Voluntária é a soma das aposentadorias por tempo de contribuição e por idade 
trabalhadores no RPPS é urbano (Pessoa; Tafner, 2006).

Apesar de as condições de saúde no Brasil não tivessem apresentado mudanças que justificassem uma alteração no quadro de invalidez, ainda cabe avaliar a série do número de acidentes laborais, ${ }^{9}$ pois os acidentes de trabalho poderiam afetar o número e incidência de trabalhadores com invalidez permanente.

\section{Gráfico 7 Logaritmo natural do número de aposentadorias por invalidez com eixo vertical esquerdo para o RPPS e eixo vertical direito para o RGPS, 2001 a 2012}

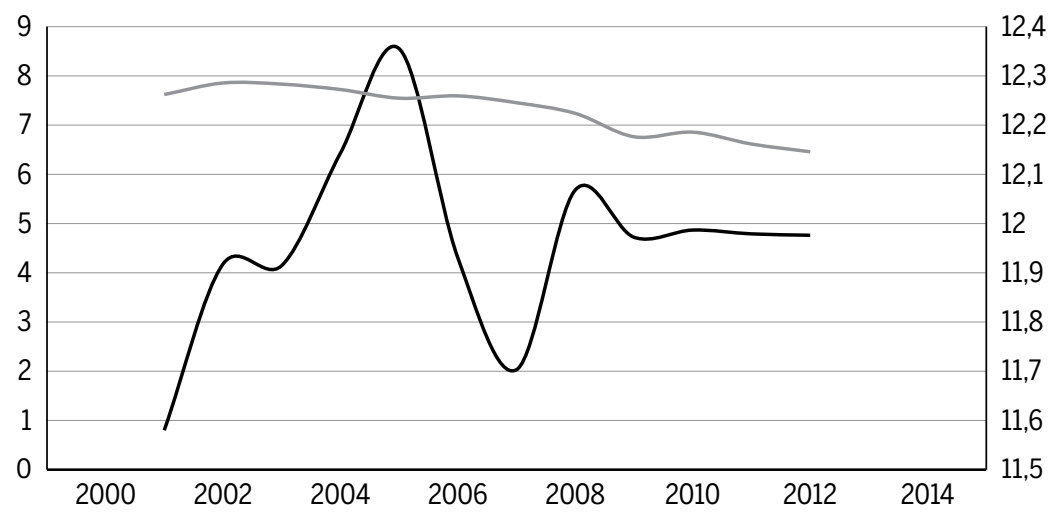

_ Invalidez na Zona Urbana do RGPS

Invalidez no RPPS

Fonte: Elaboração própria com dados do BEP/MPOG e do AEPS InfoLogo.

Conforme o Gráfico 8 mostra, há um aumento no número de acidentes de trabalho nos dois regimes, o que deve ter afetado os casos de invalidez registrados e, consequentemente, o número de aposentadorias por invalidez nos dois regimes. Com isso, fica claro que a simples análise gráfica apresenta limitações importantes que impedem se chegar a uma razão definitiva para a queda nas aposentadorias por invalidez no RPPS após a EC 41/2003. De modo a contornar isso, será necessário efetuar análises com base em métodos mais sofisticados, como os utilizados a seguir.

9 O cômputo da data do acidente que provoca uma incapacidade permanente é a do início do recebimento do benefício, por isso, podem-se usar os dados dos acidentes ocorridos no período como parâmetro do número de benefícios concedidos devido à invalidez acidentária. 
Gráfico 8 Logaritmo natural do número mensal de acidentes de trabalho na administração pública e demais setores CNAE da economia, janeiro de 2001 a dezembro de 2012

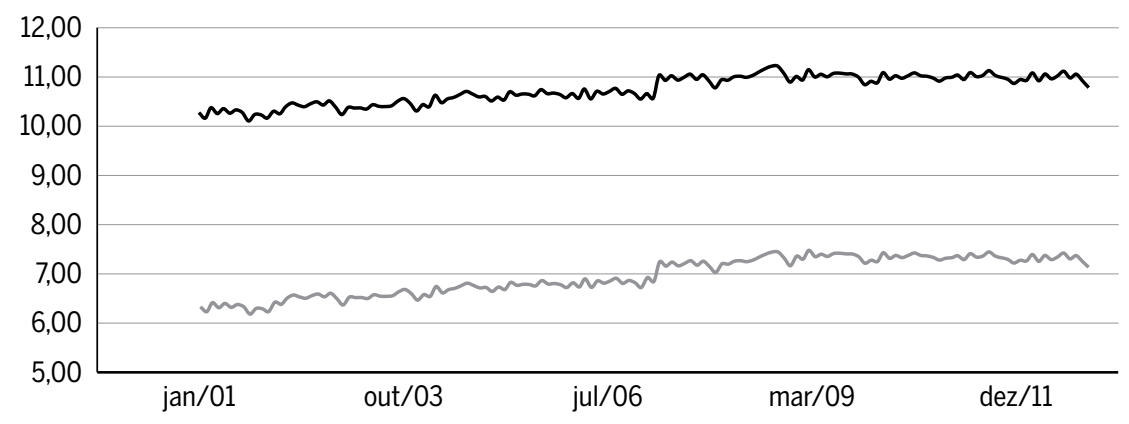

- Acidente de Trabalho nos demais setores

Acidente de Trabalho na Adm. pública, defesa e seguridade social

Fonte: Elaboração própria com dados do AEPS InfoLogo.

\subsection{Estimação do impacto da EC 41/2003}

Os métodos de avaliação de impacto podem ser classificados como experimentais ou não experimentais. No caso de métodos experimentais, mensuram-se os impactos comparando-se os resultados daqueles que foram selecionados para receber o tratamento, ou de participantes, e os resultados daqueles que não foram selecionados para receber o tratamento ou não participantes, sendo tal seleção aleatória (Foguel, 2012).

O método não experimental tenta se aproximar do idealizado método experimental, lançando mão de vários procedimentos estatísticos como, por exemplo, o Método de diferença em diferenças (DD) ou difference in differences. O método DD é simples e se baseia na observação de dois grupos em dois momentos diferentes. Um dos grupos é exposto ao tratamento no segundo período, mas não no primeiro, enquanto o segundo grupo não é exposto em momento algum. Então, a variação ocorrida no grupo de controle é excluída do grupo estudado na tentativa de eliminar os efeitos causados por outras tendências na conjuntura econômica no período analisado (Imbens; Wooldridge, 2007).

Com o uso dessa abordagem, os problemas relacionados com omissões de variáveis, como impactos causados por alterações em outras leis e 
nas condições do mercado de trabalho, ou com medições incorretas, como mudanças nos métodos de pesquisa, ou ainda nas tendências dos resultados, como o comportamento da conjuntura econômica, são reduzidos ou até eliminados (Meyer, 1995).

Em relação à escolha das variáveis, utilizamos o número e incidência de aposentadoria por invalidez. De fato, como a proporção de aposentadorias por invalidez no RPPS é calculada com o número de todas as aposentadorias no denominador; por exemplo, o aumento do número de aposentadorias programadas antes de 2004, conforme ilustrado no Gráfico 5, acaba por mascarar o efeito da EC 41/2003 na série proporção de aposentadorias. Portanto, como a EC 41/2003 afetou as regras das aposentadorias programadas e por invalidez no RPPS, não conseguiríamos isolar o efeito da EC sobre as aposentadorias por invalidez se utilizássemos a série da proporção de aposentadorias por invalidez.

\subsection{Descrição dos dados}

Utilizamos no presente trabalho seis séries de dados de janeiro de 2001 a dezembro de 2012, ${ }^{10}$ quais sejam: número de aposentadorias por invalidez dos servidores civis da união vinculados ao RPPS, ${ }^{11}$ número de aposentadoria por invalidez dos trabalhadores vinculados ao RGPS, ${ }^{12}$ incidência (em \%) de aposentadorias por invalidez no RGPS, número de acidentes de trabalho total na administração pública, ${ }^{13}$ número de acidentes dos demais trabalhadores e incidência (em \%) de aposentadorias por invalidez no RPPS. Cabe lembrar que não utilizamos uma série para os trabalhadores vinculados ao RPC porque estão incluídos no grupo do RGPS. O nome das variáveis e suas estatísticas descritivas estão na Tabela 1.

10 Embora houvesse dados de 2013 para o RPPS, durante a elaboração deste estudo os dados referentes ao RGPS ainda estavam indisponíveis.

11 Dados oriundos do Siape e apresentados nas Tabelas "Evolução do quantitativo de aposentadorias civis da União - SIAPE" dos BEP/ MPOG.

12 Como o trabalho urbano assemelha-se mais ao praticado no serviço público, esse será o perfil do RGPS utilizado.

13 Grupo CNAE "Administração Pública, Defesa e Seguridade Social”, o que inclui os militares, ao contrário dos dados previdenciários anteriores. Para obter a série mês a mês, o percentual anual de participação do código selecionado foi encontrado, servindo como ponderação da série por atividade total, a única apresentada mensalmente. 
Tabela 1 Variáveis e suas estatísticas descritivas no período de janeiro de 2001 a dezembro de 2012

\begin{tabular}{|c|c|c|c|c|c|}
\hline Variáveis & 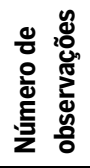 & Média & $\begin{array}{l}\text { Desvio } \\
\text { Padrão }\end{array}$ & Mínimo & Máximo \\
\hline $\begin{array}{l}\text { Número de aposentadorias por invalidez } \\
\text { no RGPS (demais grupos CNAE exceto } \\
\text { "Administração Pública, Defesa e Seguri- } \\
\text { dade Social”) }\end{array}$ & 144 & $13.952,88$ & $3.697,69$ & 3.696 & 26.473 \\
\hline $\begin{array}{l}\text { Incidência (em \%) de aposentadorias } \\
\text { por invalidez no RGPS (número de } \\
\text { aposentadorias por invalidez no RGPS/ } \\
\text { número médio mensal de contribuintes } \\
\text { empregados*100) }\end{array}$ & 144 & 0,592 & 0,201 & 0,205 & 1,230 \\
\hline $\begin{array}{l}\text { Número de acidentes de trabalho no } \\
\text { RGPS ou grupos CNAE exceto grupo } \\
\text { CNAE "Administração Pública, Defesa e } \\
\text { Seguridade Social” }\end{array}$ & 144 & $47.876,53$ & $13.077,74$ & 24.401 & 74.435 \\
\hline $\begin{array}{l}\text { Número de aposentadorias por invalidez } \\
\text { no RPPS (grupo CNAE “Administração } \\
\text { Pública, Defesa e Seguridade Social”) }\end{array}$ & 144 & 115,53 & 51,53 & 16 & 367 \\
\hline $\begin{array}{l}\text { Incidência (em \%) de aposentadorias por } \\
\text { invalidez no RPPS (número de aposen- } \\
\text { tadorias por invalidez no RPPS/número } \\
\text { médio mensal de servidores ativos da } \\
\text { união, exceto militares*100) }\end{array}$ & 144 & 0,104 & 0,050 & 0,014 & 0,341 \\
\hline $\begin{array}{l}\text { Número de acidentes de trabalho na } \\
\text { administração pública }\end{array}$ & 144 & $1.333,71$ & 537,37 & 499 & 2.236 \\
\hline
\end{tabular}

Fonte: BEP/MPOG e Anuário Estatístico da Previdência Social (AEPS) InfoLogo.

\subsection{Estimando DD, $\mathrm{E}_{\mathrm{dd}}$}

O Estimador de diferença em diferenças $\left(E_{d d}\right)$ se baseia no cálculo de uma dupla subtração ou diferença. A primeira é a diferença entre a média da variável de resultado entre os períodos anterior e posterior ao tratamento, tanto para os participantes quanto para os não participantes. A segunda é a diferença desse resultado entre os dois grupos. $O$ cálculo do estimador é demonstrado na Tabela 2. 
Tabela 2 Estimador de diferença em diferenças $\left(E_{d d}\right)$

\begin{tabular}{lrr|r}
\hline & $\begin{array}{r}\text { Grupo } \\
\text { Tratado }\end{array}$ & $\begin{array}{r}\text { Grupo } \\
\text { Não-Tratado }\end{array}$ & Diferenças \\
\hline Antes & $\mathrm{T}^{\mathrm{a}}$ & $\mathrm{N}^{\mathrm{a}}$ & $\mathrm{T}^{\mathrm{a}}-\mathrm{N}^{\mathrm{a}}$ \\
\hline Depois & $\mathrm{T}^{\mathrm{d}}$ & $\mathrm{N}^{\mathrm{d}}$ & $\mathrm{T}^{\mathrm{d}}-\mathrm{N}^{\mathrm{d}}$ \\
\hline Diferenças & $\mathrm{T}^{\mathrm{d}}-\mathrm{T}^{\mathrm{a}}$ & $\mathrm{N}^{\mathrm{d}}-\mathrm{N}^{\mathrm{a}}$ & $\mathrm{E}_{\mathrm{dd}}=\left(\mathrm{T}^{\mathrm{d}}-\mathrm{T}^{\mathrm{a}}\right)-\left(\mathrm{N}^{\mathrm{d}}-\mathrm{N}^{\mathrm{a}}\right)=\left(\mathrm{T}^{\mathrm{d}}-\mathrm{N}^{d}\right)-\left(\mathrm{T}^{\mathrm{a}}-\mathrm{N}^{\mathrm{a}}\right)$ \\
\hline
\end{tabular}

Fonte: Elaboração própria.

No presente estudo, os grupos estudados são o dos trabalhadores vinculados ao RPPS ou grupo que recebeu o tratamento (T) e o grupo dos trabalhadores vinculados ao RGPS ou grupo controle $(\mathrm{N})$. A entrada em vigor da EC 41/2003 é o tratamento. Cabe ressaltar que as alterações introduzidas pela EC 41/2003 não afetam o grupo vinculado ao RGPS, sendo o comportamento do número observado de aposentadoria por invalidez para esse grupo aquele esperado para o grupo tratado se não tivesse recebido o tratamento. Aplicando a metodologia da Tabela 1 às séries do logaritmo natural do número de aposentadorias por invalidez no RPPS e RGPS, obtém-se a estimativa do Edd, como apresentado na Tabela 3.

Tabela 3 Média e erro-padrão do logaritmo do número de aposentadorias por invalidez por grupo e período

\begin{tabular}{lrrrr}
\hline & RPPS & RGPS & Diferenças \\
\hline \multirow{2}{*}{ Antes } & 5,028 & 9,343 & $* * *-4,315$ \\
& $(0,051)$ & $(0,058)$ & $(0,077)$ \\
\hline \multirow{2}{*}{ Depois } & 4,519 & 9,557 & $* * *-5,039$ \\
& $(0,044)$ & $(0,025)$ & $(0,051)$ \\
Diferenças & $* * * 0,510$ & $* * * 0,214$ & $\mathrm{E}_{\mathrm{dd}}=-0,724$ \\
\hline
\end{tabular}

Fonte: Elaboração própria.

Notas: erros-padrão entre parênteses; ${ }^{* *}$ Denota significante ao nivel de $1 \%$ pelo teste t para igualdade de médias de duas populações de mesma variância desconhecida.

As estimativas na Tabela 3 revelam que, no período, há uma redução de $39,95 \%(=(\exp (-0,510)-1) \times 100)$ nas aposentadorias por invalidez no RPPS. No caso das aposentadorias no RGPS (grupo controle) há um aumento de $23,86 \%(=(\exp (0,214)-1) \times 100)$ nas aposentadorias (efeito placebo). Finalmente, ao subtrair-se o efeito placebo do efeito do tratamento no grupo 
tratado, obtém-se o efeito do tratamento ou estimativa diferença em diferenças que, no caso, é de redução de 51,52\% (=(-(exp(-0,724)-1))×100) nas aposentadorias por invalidez no RPPS.

O Gráfico 9 ilustra o efeito do tratamento com uma seta preta, apresentando o logaritmo natural das aposentadorias no RGPS e no RPPS, antes e depois da EC 41/2003, respectivamente, com as linhas com rótulos: "Grupo Não-Tratado (esperado)" e "Grupo Tratado (ocorrido)". Caso não tivesse havido a EC 41/2003, seria esperado um aumento no RPPS como o observado no grupo controle, o que é ilustrado com a linha "Grupo Tratado (esperado)". Contudo, devido a EC 41/2003, o que de fato se observa é ilustrado pela linha "Grupo Tratado (ocorrido)", a qual apresenta a queda no número das aposentadorias por invalidez observado no RPPS.

Gráfico 9 Logaritmo do número de aposentadorias por invalidez no grupo tratado e grupo não tratado, antes e depois do tratamento, EC 41/2003

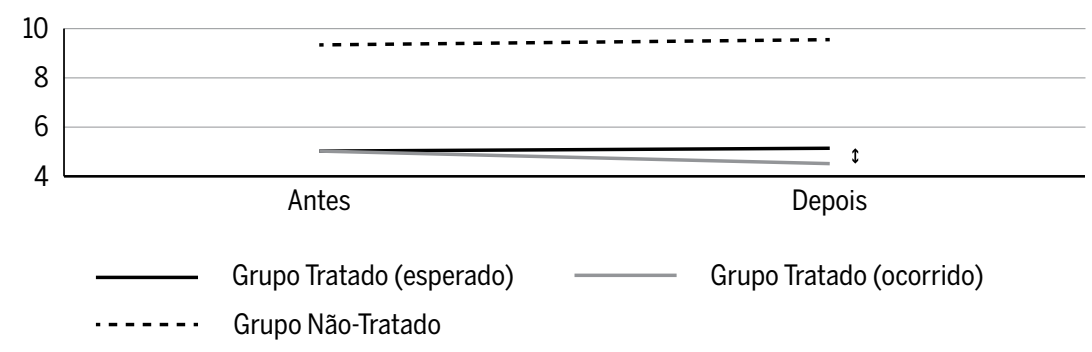

Fonte: Elaboração própria.

\subsection{Estimando DD por regressões}

Obtivemos estimativas diferença em diferenças também com base na especificação (1) do modelo econométrico.

$$
N A_{i t}=\beta_{0}+\beta_{1} \cdot R P P_{i t}+\beta_{2} \cdot \text { Depois }_{i t}+\beta_{3} \cdot\left(R P P_{i t} \cdot \text { Depois }_{i t}\right)+v_{i}+u_{i t}
$$

Em que $i$ denota, respectivamente, o regime de aposentadoria do trabalhador representativo, RPPS e RGPS; $t=1, \ldots, 144$, tal que $t$ é 1 em janeiro de 2001, 37, em janeiro de 2004 e 144 em dezembro de 2012; $N A_{i t}$ é o logaritmo natural do número de aposentados por invalidez no regime $i$ no tempo $t$; 
$\beta_{0}$ é o intercepto do modelo; RPP é uma variável dicotômica ou dummy que recebe 1 para o RPPS e 0 caso contrário; depois é uma variável dummy que recebe 1 de janeiro de 2004 ( $\mathrm{t}=37$ ) até dezembro de 2012 e 0, caso contrário); $R P P_{i t} \times$ depois $_{i t}$ é uma variável de interação entre RPP e depois; $v_{i}$ denota o efeito fixo do $i$-ésimo indivíduo o qual, como tal, é invariante no tempo; no caso do modelo de efeitos aleatórios $v_{i}$ denota erros aleatórios, em princípio, identicamente e independentemente distribuídos com média zero e variância constante (Baltagi, 2005; Imbens; Wooldridge, 2007); no caso do modelo Mínimos Quadrados Empilhados (MOE ou pooled), $v_{i}$ é tido como uma constante para todo $i$; e $\mathrm{u}_{i t}$ é o termo de erro estocástico. Finalmente, o parâmetro $\beta_{3}$ é o efeito do tratamento ou efeito diferença em diferenças.

Os resultados das estimações dos modelos em (1) estão na Tabela 4.

Tabela 4 Resultados das estimações dos modelos em (1)

\begin{tabular}{lrrrr}
\hline Variável & $\begin{array}{r}\text { Mínimos Quadrados } \\
\text { Empilhados (MQE) } \\
\text { ou Polled OLS }\end{array}$ & $\begin{array}{r}\text { Efeitos } \\
\text { Fixos }\end{array}$ & $\begin{array}{r}\text { Efeitos } \\
\text { Aleatórios }\end{array}$ \\
\hline RPP & $* * *-4,315$ & 0 & $* * *-4,315$ \\
\cline { 2 - 4 } Depois & $(8,42 \mathrm{e}-14)$ & $()$. & $(8,49 \mathrm{e}-15)$ \\
\hline RPP $\times$ Depois & $* * * 0,214$ & $* * * 0,214$ & $* * * 0,214$ \\
\hline Intercepto & $(8,02 \mathrm{e}-14)$ & $(5,72 \mathrm{e}-16)$ & $(8,23 \mathrm{e}-15)$ \\
\hline Número de observações & $* * *-0,724$ & $* * *-0,724$ & $* * *-0,724$ \\
\hline$R^{2}$ & $(1,05 \mathrm{e}-13)$ & $(3,21 \mathrm{e}-15)$ & $(8,42 \mathrm{e}-15)$ \\
\hline
\end{tabular}

Fonte: Elaboração própria.

Notas: Números em parênteses são erros-padrão cluster-robust, ou seja, robustos à heterocedasticidade e correlação serial dentro do grupo; ${ }^{* * *}$ denota significante ao nível de $1 \%$.

Com base nos resultados da Tabela 4, constata-se que as estimativas são as mesmas nos três modelos, como antecipávamos, mas os erros-padrão são diferentes. No caso do modelo efeitos fixos, o coeficiente de RPP não pode ser estimado devido à colinearidade perfeita de RPP com os efeitos fixos.

Com base na Tabela 4, estima-se como antes um aumento de $23,86 \%$ $(=\exp (0,214)-1) \times 100)$ para as aposentadorias por invalidez no RGPS no 
período pós EC 41/2003 (efeito placebo), ou seja, o que retrata um cenário de aumento nas aposentadorias por invalidez. Contudo, a estimativa do efeito do tratamento nos tratados é de redução de 39,95\% (=-(exp $(-0,724+0,214)-1) \times 100)$ nas aposentadorias por invalidez no RPPS, o que seria uma subestimativa do efeito do tratamento, tendo em vista que se dá em um cenário de alta (efeito placebo). Assim, estimativa real do efeito da EC 41/2003 nas aposentadorias por invalidez no RPPS deve descontar o efeito placebo. Logo, a estimativa diferença em diferenças ou do tratamento é, como antes, de redução de $51,52 \%(=(-(\exp (-0,724)-1)) \times 100)$ no número de aposentadorias por invalidez no RPPS.

\subsection{Estimando DD com regressões com variáveis adicionais de controle}

Nesta etapa, realiza-se a análise da robustez dos resultados, incluindo controles adicionais nos modelos (1). Seguindo Jayachandran et al. (2010), adicionam-se a variável tendência, $t$, de modo a controlar para fatores com tendência temporal que explicam as aposentadorias por invalidez, mas que não podem ser explicitamente incluídos nos modelos devido à indisponibilidade de dados. Por exemplo, a tendência de melhora e/ou piora nas condições de saúde do trabalhador e/ou nas condições de trabalho no RGPS e RPPS ao longo do tempo devem explicar as aposentadorias por invalidez, mas não podem ser explicitamente incluídas no modelo devido à indisponibilidade de dados para essas variáveis. Ainda seguindo Jayachandran et al. (2010), incluímos as variáveis de interação, $R P P \times t$ e $R P P \times D e p o i s \times t$, o que permite que os fatores com tendência temporal que explicam as aposentadorias possam ter efeitos distintos nos grupos (RPPS e RPGS) e períodos (antes e depois da EC 41/2003).

Por fim, adicionam-se a variável de controle logaritmo natural do número de acidentes de trabalho (lnac) e as suas interações, $R P P \times \operatorname{lnac} \mathrm{e}$ $R P P \times$ Depois $\times$ lnac de modo a permitir que os casos de acidentes de trabalho possam ter efeitos distintos nos grupos (RPPS e RPGS) e períodos (antes e depois da EC 41/2003). As estimativas obtidas estão na Tabela 5.

Com base nos resultados da Tabela 5, estima-se um aumento, como antes, mas agora de $20,32 \%(=(\exp (0,185)-1) \times 100)$ no número de aposentadorias por invalidez no RGPS no período pós EC 41/2003 (efeito place- 
bo). Portanto, mesmo controlando para tendência e acidentes no trabalho, o aumento nas aposentadorias por invalidez no Brasil permanece, o que sugere robustez dos resultados.

Tabela 5 Resultados das estimações dos modelos (1) acrescidos de variáveis de controle

\begin{tabular}{|c|c|c|c|}
\hline Variável & $\begin{array}{r}\text { Mínimos Quadrados } \\
\text { Empilhados (MQE) } \\
\text { ou Polled OLS }\end{array}$ & $\begin{array}{r}\text { Efeitos } \\
\text { Fixos }\end{array}$ & $\begin{array}{r}\text { Efeitos } \\
\text { Aleatórios }\end{array}$ \\
\hline \multirow{2}{*}{$R P P$} & $* * *-1,991$ & 0 & $* * *-1,991$ \\
\hline & $(1,02 \mathrm{e}-09)$ & $()$. & $(9,08 \mathrm{e}-11)$ \\
\hline \multirow{2}{*}{ Depois } & $* * * 0,185$ & $* * * 0,185$ & $* * * 0,185$ \\
\hline & $(1,26 \mathrm{e}-12)$ & $(1,31 \mathrm{e}-14)$ & $(1,10 \mathrm{e}-12)$ \\
\hline \multirow{2}{*}{$R P P \times$ Depois } & $* * * 3,432$ & $* * * 3,432$ & $* * * 3,432$ \\
\hline & $(1,07 e-09)$ & $(2,61 \mathrm{e}-10)$ & $(5,86 e-11)$ \\
\hline \multirow{2}{*}{$t$} & $* * *-0,00305$ & $* * *-0,00305$ & $* * *-0,00305$ \\
\hline & $(5,04 \mathrm{e}-14)$ & $(2,24 \mathrm{e}-17)$ & $(3,43 e-14)$ \\
\hline \multirow{2}{*}{$R P P \times t$} & $* * * 0,0107$ & $* * * 0,0107$ & *** 0,0107 \\
\hline & $(1,67 e-12)$ & $(3,92 \mathrm{e}-13)$ & $(1,02 \mathrm{e}-13)$ \\
\hline \multirow{2}{*}{$R P P \times$ Depois $\times t$} & $* * *-0,018$ & ${ }^{* * *}-0,018$ & $* * *-0,018$ \\
\hline & $(1,76 \mathrm{e}-12)$ & $(4,27 \mathrm{e}-13)$ & $(9,90 \mathrm{e}-14)$ \\
\hline \multirow{2}{*}{ Inac } & $* * * 0,484$ & $* * * 0,484$ & ${ }^{* * *} 0,484$ \\
\hline & $(9,87 \mathrm{e}-12)$ & $(1,72 \mathrm{e}-14)$ & $(6,95 \mathrm{e}-12)$ \\
\hline \multirow{2}{*}{$R P P \times \ln a c$} & $* * *-0,103$ & $* * *-0,103$ & $* * *-0,103$ \\
\hline & $(1,60 \mathrm{e}-10)$ & $(3,70 \mathrm{e}-11)$ & $(1,13 e-11)$ \\
\hline \multirow{2}{*}{$R P P \times$ Depois $\times \operatorname{lnac}$} & $* * *-0,458$ & $* * *-0,458$ & $* * *-0,458$ \\
\hline & $(1,69 \mathrm{e}-10)$ & $(4,11 e-11)$ & $(9,24 \mathrm{e}-12)$ \\
\hline \multirow{2}{*}{ Intercepto } & *** 4,390 & $* * * 3,394$ & $* * * 4,390$ \\
\hline & $(1,01 \mathrm{e}-10)$ & $(1,17 \mathrm{e}-10)$ & $(7,13 e-11)$ \\
\hline Número de observações & 288 & 288 & 288 \\
\hline$R^{2}$ & 0,987 & 0,490 & 0,987 \\
\hline
\end{tabular}

Fonte: Elaboração própria.

Notas: Números em parênteses são erros-padrão cluster-robust, ou seja, robustos à heterocedasticidade e correlação serial dentro do grupo (RPPS ou RGPS); ***denota significante ao nível de $1 \%$.

A estimativa diferença em diferenças ou efeito do tratamento é o resultado da soma das estimativas do coeficiente da variável $R P P \times D e p o i s$ com o coeficiente de $R P P \times D e p o i s \times t$ multiplicado pela tendência, e com o coeficiente 
da variável $R P P \times D e p o i s \times \operatorname{lnac}$ multiplicado por lnac. Em suma, a estimativa diferença em diferenças é 3,432-0,018t-0,458lnac e, assim, depende do número de acidentes de trabalho no RPPS. Por exemplo, tomando os níveis de Inac e $t$ de janeiro de 2004 a dezembro de 2012 no RPPS, a estimativa diferença em diferenças média é de redução de $72,81 \%$ nas aposentadorias por invalidez devido à EC 41/2003.

Estima-se, ainda, com base na estimativa diferença em diferenças 3,432-0,018t-0,458/nac, que cada $1 \%$ de aumento dos casos de acidentes de trabalho no RPPS gera um aumento de $0,458 \%$ na redução resultante da EC 41/200, o que poderia ser justificado se o maior número de servidores acidentados optasse por permanecer na ativa mesmo elegíveis para a invalidez. Em suma, o aumento no número de acidentes de trabalho no RPPS acaba por, ceteris paribus, aumentar o efeito redutor da EC 41/2003 no número de aposentadorias por invalidez no RPPS.

A estimativa da elasticidade dos acidentes de trabalho nas aposentadorias por invalidez é $0,484 \%$ no RGPS, tal que se estima que cada $1 \%$ de aumento no número de acidentes aumenta em $0,484 \%$ os casos de aposentadorias por invalidez no RGPS. No caso do RPPS, tal elasticidade é $0,381 \%$ $(=(0,484-0,103))$ para o período anterior à EC 41/2003, e - $0,077 \%$ (=0,3810,458 ) para o período posterior à EC $41 / 2003$, o que pode ser justificado se servidores acidentados estiverem conseguindo permanecer na ativa.

Como o número de aposentadorias por invalidez pode se alterar devido ao menor ou maior número de potenciais beneficiários, investiga-se a seguir se isso poderia ter afetado os resultados obtidos até então. Para tanto, os modelos da Tabela 5 foram reestimados, utilizando o logaritmo natural da incidência (em \%) de aposentadorias por invalidez (vide descrição na Tabela 1) como variável dependente. Os resultados das estimações estão na Tabela 6.

Com base nos resultados na Tabela 6 , estima-se um aumento ceteris paribus de $20,80 \%(=(\exp (0,189)-1) \times 100)$ na incidência de aposentadorias por invalidez no RGPS no período pós EC 41/2003 (efeito placebo). Ou seja, há também um cenário de aumento na incidência das aposentadorias por invalidez.

A estimativa diferença em diferenças ou efeito do tratamento é 0,204-0,002t-0,051 lnac, tal que tomando os valores de lnac e $t$ de janeiro de 2004 a dezembro de 2012 no RPPS, obtemos uma estimativa diferença em diferenças média no sentido de redução de 31,93\% na incidência de aposentadorias por invalidez devido à EC 41/2003. Ainda, para cada 1\% 
de aumento nos casos de acidentes de trabalho no RPPS, estima-se um aumento de $0,051 \%$ na redução devido à EC 41/2003 na incidência de aposentadorias por invalidez no RPPS.

Tabela 6 Resultados das estimações dos modelos na Tabela 5 quando a variável dependente é o logaritmo natural da Incidência (em \%) de aposentadorias por invalidez

\begin{tabular}{|c|c|c|c|}
\hline Variável & $\begin{array}{r}\text { Mínimos Quadrados } \\
\text { Empilhados (MQE) } \\
\text { ou Polled OLS }\end{array}$ & $\begin{array}{r}\text { Efeitos } \\
\text { Fixos }\end{array}$ & $\begin{array}{r}\text { Efeitos } \\
\text { Aleatórios }\end{array}$ \\
\hline \multirow{2}{*}{$R P P$} & $0,912^{* * *}$ & 0 & $0,912^{* * *}$ \\
\hline & $(4,81 \mathrm{e}-11)$ & (.) & $(1,83 e-11)$ \\
\hline \multirow{2}{*}{ Depois } & $0,189 * * *$ & $0,189 * * *$ & $0,189 * * *$ \\
\hline & $(7,59 \mathrm{e}-14)$ & $(4,97 \mathrm{e}-16)$ & $(2,82 e-13)$ \\
\hline \multirow{2}{*}{$R P P \times$ Depois } & $0,204^{* * *}$ & $0,204^{* * *}$ & $0,204^{* * *}$ \\
\hline & $(5,18 \mathrm{e}-11)$ & $(2,88 \mathrm{e}-11)$ & $(5,43 e-12)$ \\
\hline \multirow{2}{*}{$t$} & $-0,005^{* * *}$ & $-0,005^{* * *}$ & $-0,005^{* * *}$ \\
\hline & $(2,47 \mathrm{e}-15)$ & $(2,91 e-17)$ & $(8,33 e-15)$ \\
\hline \multirow{2}{*}{$R P P \times t$} & $0,006^{* * *}$ & $0,006^{* * *}$ & $0,006^{* * *}$ \\
\hline & $(8,10 \mathrm{e}-14)$ & $(4,31 \mathrm{e}-14)$ & $(1,09 e-14)$ \\
\hline \multirow{2}{*}{$R P P \times$ Depois $\times t$} & $-0,002^{* * *}$ & $-0,002^{* * *}$ & $-0,002^{* * *}$ \\
\hline & $(8,61 \mathrm{e}-14)$ & $(4,71 \mathrm{e}-14)$ & $(7,43 e-15)$ \\
\hline \multirow{2}{*}{ Inac } & $0,169 * * *$ & $0,169 * * *$ & $0,169 * * *$ \\
\hline & $(4,98 \mathrm{e}-13)$ & $(4,84 \mathrm{e}-15)$ & $(1,71 e-12)$ \\
\hline \multirow{2}{*}{$R P P \times \ln a c$} & $-0,135^{* * *}$ & $-0,135^{* * *}$ & $-0,135^{* * *}$ \\
\hline & $(7,57 \mathrm{e}-12)$ & $(4,08 \mathrm{e}-12)$ & $(1,89 \mathrm{e}-12)$ \\
\hline \multirow{2}{*}{$R P P \times$ Depois $\times \operatorname{lnac}$} & $-0,051^{* * *}$ & $-0,051^{* * *}$ & $-0,051^{* * *}$ \\
\hline & $(8,16 \mathrm{e}-12)$ & $(4,54 \mathrm{e}-12)$ & $(8,50 \mathrm{e}-13)$ \\
\hline \multirow{2}{*}{ Intercepto } & $-1,013^{* * *}$ & $-0,557^{* * *}$ & $-1,013^{* * *}$ \\
\hline & $(5,11 \mathrm{e}-12)$ & $(1,29 \mathrm{e}-11)$ & $(1,76 \mathrm{e}-11)$ \\
\hline Número de observações & 288 & 288 & 288 \\
\hline$R^{2}$ & 0,830 & 0,351 & 0,830 \\
\hline
\end{tabular}

Fonte: Elaboração própria.

Notas: Números em parênteses são erros-padrão cluster-robust, ou seja, robustos à heterocedasticidade e correlação serial dentro do grupo (RPPS ou RGPS); ***denota significante ao nível de $1 \%$.

Por fim, estima-se uma elasticidade de $0,169 \%$ dos acidentes de trabalho na incidência de aposentadorias por invalidez no RGPS. No caso do RPPS, 
a elasticidade acidentes de trabalho é $0,034 \%(=(0,169-0,135)$ no período anterior à EC 41/2003, e -0,017\% (=0,034-0,051) no período posterior.

\subsection{Avaliação dos resultados}

As estimativas dos modelos com o número e incidência de aposentadorias por invalidez levam a resultados qualitativamente idênticos, o que reforça sua robustez e, assim, leva à conclusão de que a EC 41/2003 reduziu o número em $72,81 \%$ e a incidência em $31,93 \%$ das aposentadorias por invalidez no RPPS. Com base nisso, concluímos que a alteração introduzida pela EC 41/2003, ao desincentivar a aposentadoria por invalidez, reduziu o risco moral devido a casos de servidores que se aposentavam por invalidez, mesmo quando não eram elegíveis. Por outro lado, os resultados também indicam que a EC 41/2003 aumentou o risco moral devido a casos de servidores que apesar de elegíveis à aposentadoria por invalidez, permanecem na ativa.

De toda forma, a EC 41/2003 permitiu reduzir os gastos orçamentários ao tornar possível postergar a contratação de servidores para substituir aqueles que se aposentariam por invalidez, e gerou uma economia nos custos previdenciários devido à redução no número de benefícios concedidos e no valor do benefício pago àqueles que se aposentaram por invalidez. Considerando apenas o primeiro efeito e a estimativa de $72,81 \%$ de redução nas aposentadorias por invalidez no RPPS após a EC 41/2003, estimamos que 259.614 servidores deixaram de se aposentar por invalidez de 2004 a 2012, o que, supondo a reposição imediata deles, corresponde a uma economia total de R $\$ 15,1$ bilhões ${ }^{14}$ no período 2004 a 2012.

\section{Conclusão}

Este trabalho testou a hipótese de que a EC 41/2003 não afetou o comportamento dos servidores públicos federais e, consequentemente, o número

14 Tal valor é o produtório, no período de 2004 a 2012, da soma da renda média dos servidores ativos (gastos orçamentários) e dos aposentados (custos previdenciários) com a estimativa do número de servidores que deixaram de se aposentar em decorrência da EC 41/2003. O cálculo supõe a reposição imediata dos servidores aposentados, e desconsidera que há um período de tempo entre a vacância de um cargo público e sua reocupação, além da própria variação do quadro de pessoal, e se limita a dar uma dimensão da economia obtida. 
e incidência de aposentadorias por invalidez no RPPS. Para tanto, primeiro descreveu as alterações nas normas para aposentadoria introduzidas pela EC 41/2003, identificando o caráter restritivo delas. Em seguida, procurou detectar alterações nas condições de saúde dos brasileiros e nas regras de concessão de aposentadorias de modo a especular sobre seus efeitos na utilização de benefícios por invalidez no Brasil.

Observou-se que há manutenção ou redução na taxa de mortalidade das faixas etárias dos indivíduos em idade de trabalho, manutenção da média mensal de dias de permanência em internações hospitalares e uma tendência de queda no número de internações (Gráfico 2), o que sugere uma tendência de redução no número e incidência de aposentadorias por invalidez. Os resultados desta investigação inicial foram utilizados na definição de variáveis de controle dos modelos econométrico utilizados para comparar o comportamento dos servidores públicos (grupo tratado) com o dos trabalhadores do setor privado (grupo controle) em termos do número e incidência de aposentadorias por invalidez.

Com base na estimação de regressões de diferença em diferenças, estima-se que a mudança de regras resultou em uma redução de $72,81 \%$ no número e de $31,93 \%$ na incidência de aposentadorias por invalidez no período de 2004 a 2012. Com isso, conclui-se que a EC 41/2003 possibilitou uma redução nos gastos orçamentários ao tornar possível postergar a contratação de servidores que viriam a substituir aqueles que se aposentariam por invalidez. Ademais, a EC 41/2003 possibilitou uma economia nos custos previdenciários, uma vez que reduziu o número de benefícios concedidos e reduziu os gastos com aqueles que se aposentaram por invalidez.

\section{Referências}

BALTAGI, B. H. Econometric Analysis of Panel Data. Nova York: John Wiley \& Sons Ltd., 2005.

CAETANO, M. A. Estrutura, limitações e desafios para previdência dos servidores públicos. In: TAFNER, P.; BOTELHO, C.; ERBISTI, R. (Org.). Reforma da Previdência: a visita da velha senhora. Brasília: Gestão Pública, 2015, p. 173-189.

FOGUEL, M. Diferença em diferenças. In: FILHO, N. M. (Org.). Avaliação econômica de projetos sociais. São Paulo: Dinâmica Gráfica e Editora, p. 69-83, 2012.

IMBENS, G.; WOOLDRIDGE, J. What's new in econometrics? Difference-in-Differences Estimation. Lecture Notes 10, Cambridge: National Bureau of Economic Research, 2007.

JAYACHANDRAN, S.; LLERAS-MUNEY, A.; SMITH, K.V. Modern medicine and the twenti- 
eth century decline in mortality: evidence on the impact of sulfa drugs. American Economic Journal: Applied Economics, v. 2, n. 2, p. 118-146, 2010.

JÖNSSON, L.; PALME, M.; SVENSSON, I. Disability insurance - population health and employment in Sweden. National Bureau of Economic Research Project International Social Security, 2010.

MARCO, Z. et al. Os regimes próprios de Previdência Social: fundamentos e desafios. In: BRASIL. Ministério da Previdência Social (Org.). Previdência Social: reflexões e desafios. Coleção Previdência Social, Série Estudos, Brasília, v. 30, cap. 2, p. 39-68: MPS, 2009.

MEYER, B.D. Natural and quasi-experiments in economics. Journal of Business and Economic Statistics, v. 13, n. 2, p. 151-161, 1995.

MEZIAT FILHO, N.; SILVA, G. A. Invalidez por dor nas costas entre segurados da Previdência Social do Brasil. Revista de Saúde Pública, v. 45, n. 3, p. 494-502, 2011.

MINISTÉRIO DA PREVIDÊNCIA SOCIAL. 2014. Anuário Estatístico da Previdência Social (AEPS) InfoLogo. Disponível em <http://www.previdencia.gov.br/estatisticas/>. Acesso em: 31 jul. 2014.

MINISTÉRIO DA SAUUDE. 2014. Departamento de Informática do SUS (DATASUS). Disponível em <tabnet.datasus.gov.br>. Acesso em: 31 jul. 2014.

NAJBERG, S.; IKEDA, M. Previdência no Brasil: desafios e limites. In: GIAMBIAGI, F; MOREIRA, M. (Ed.). A economia brasileira nos anos 90. Rio de Janeiro: BNDES, cap. 3, p. 261-290, 1999.

OLIVEIRA, F. E. B. et al. O idoso e a Previdência Social. In: Os novos idosos brasileiros: muito além dos 60? Rio de Janeiro: IPEA, cap. 12, p. 411-426, 2004.

PESSOA, M. S.; TAFNER, P. S. B. Aposentadoria por invalidez dos servidores públicos civis do Poder Executivo Federal brasileiro entre 1994 e 2004. Brasília: ESAF, 2006.

ZIVOT, E.; ANDREWS, K. Further evidence on the great crash, the oil price shock, and the unit root hypothesis. Journal of Business and Economic Statistics, v. 10, n. 10, p. 251-70, 1992.

ZYLBERSTAJN, H. et al. Uma proposta para a criação de um sistema único de Previdência Social para o Brasil. Revista de Economia e Relações Internacionais. São Paulo: Faculdade de Economia da Fundação Armando Alvares Penteado, v. 8, n. 16, p. 126-144, 2010.

\section{Sobre os autores}

Helvio Antonio Pereira Marinho - helvio.marinho@previc.gov.br

Superintendência Nacional de Previdência Complementar, Brasília, DF.

Moises de Andrade Resende Filho-moisesresende@unb.br

Universidade de Brasília, Brasília, DF.

VanderMendes Lucas - vlucas@unb.br

Universidade de Brasília, Brasília, DF.

O autor agradece à PREVIC pela concessão de licença capacitação. O segundo autor agradece ao CNPq pela bolsa de produtividade em pesquisa. $\mathrm{O}$ terceiro autor agradece o apoio financeiro da FAPDF.

\section{Sobre 0 artigo}

Recebido em 26 de julho de 2015. Aprovado em 30 de junho de 2016. 